\title{
Estimation of Broadband Shock Noise Reduction in Turbulent Jets by Water Injection
}

\author{
Max Kandula' \\ ASRC Aerospace, NASA Kennedy Space Center, Florida 32899, USA \\ Michael J. Lonergan ${ }^{2}$ \\ NASA Kennedy Space Center, Florida 32899, USA
}

The concept of effective jet properties introduced by the authors (AIAA-2007-3645) has been extended to the estimation of broadband shock noise reduction by water injection in supersonic jets. Comparison of the predictions with the test data for cold underexpanded supersonic nozzles shows a satisfactory agreement. The results also reveal the range of water mass flow rates over which saturation of mixing noise reduction and existence of parasitic noise are manifest.

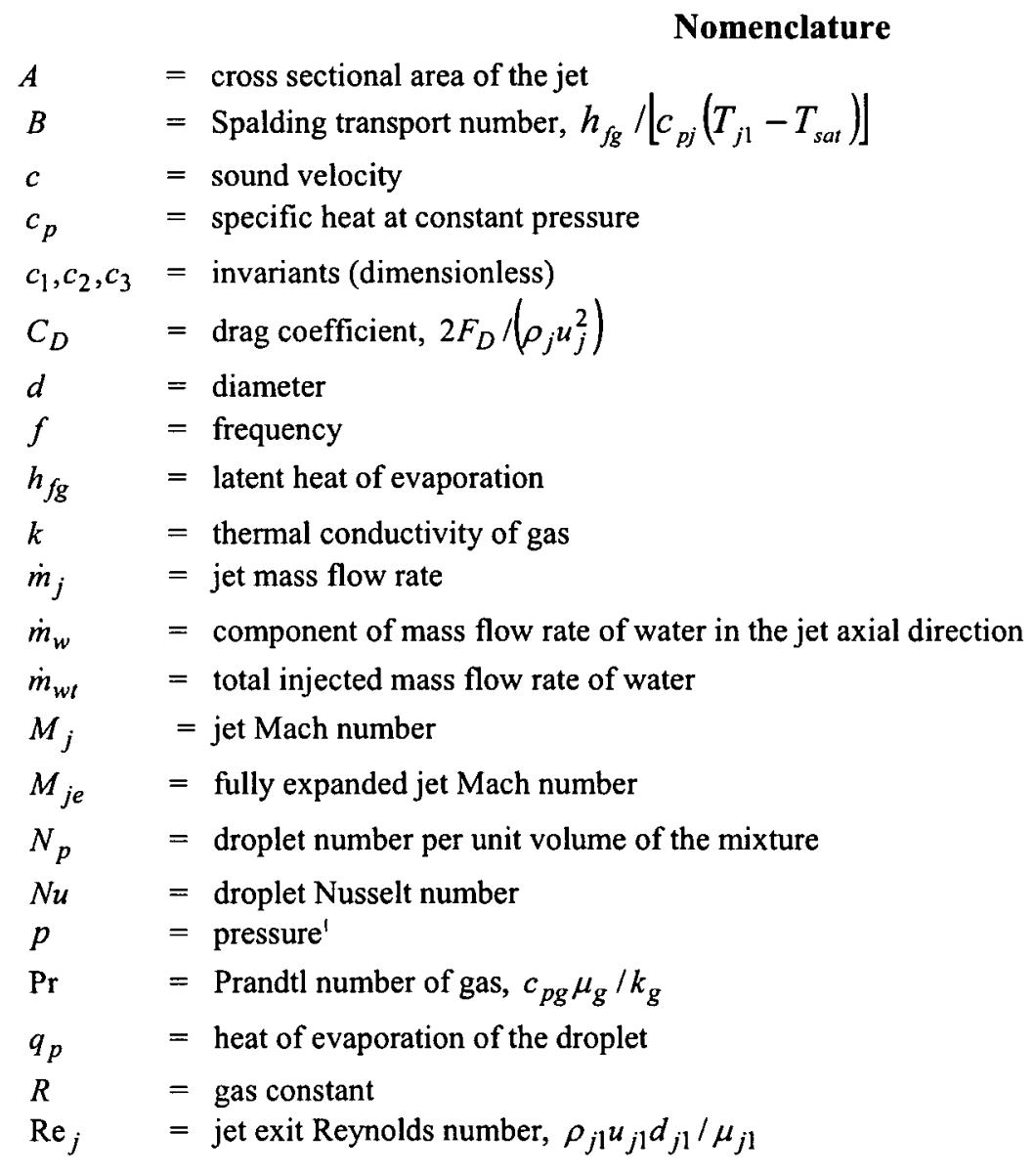

\footnotetext{
${ }^{1}$ Subject Matter Expert, Mailstop ASRC-5211, Associate Fellow AIAA.

${ }^{2}$ Chief, Structures and Analysis Branch, Mailstop NE-M1.
} 


$$
\begin{array}{ll}
\operatorname{Re}_{p} & =\text { droplet Reynolds number, } \rho_{j 1}\left|u_{j 1}-u_{p}\right| d_{p} / \mu_{j 1} \\
S P L & =\text { sound pressure level } \\
T & =\text { temperature } \\
T_{j e} & =\text { equivalent gas temperature for heat transfer } \\
u & =\text { velocity in the streamwise direction } \\
x & =\text { axial distance from the nozzle exit plane } \\
x_{i} & =\text { length of potential core in the jet }
\end{array}
$$

\section{Greek Symbols}

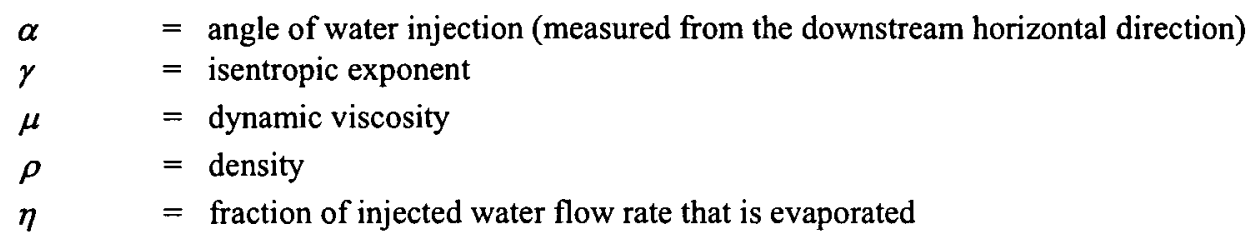

\section{Subscripts}

$\begin{array}{ll}a & =\text { ambient fluid } \\ c r & =\text { critical } \\ D & =\text { drag } \\ g & =\text { gas } \\ j & =\text { jet } \\ l & =\text { liquid } \\ p & =\text { droplet (or particle) } \\ \text { sat } & =\text { saturation } \\ t & =\text { stagnation } \\ w & =\text { injected water } \\ 1 & =\text { jet exit } \\ 2 & =\text { effective jet property }\end{array}$

\section{Introduction}

$T^{3}$ hree distinct components of noise are present in supersonic jets: turbulent mixing noise, Mach wave radiation, and broadband shock associated noise (Crighton ${ }^{1}$ ). Generally the shock-associated noise includes both broadband shock noise and discrete screech tones ${ }^{2,3}$ (Figs. 1, 2). Both the broadband shock noise and screech tones are associated with imperfectly expanded jets. The high noise levels (160 to $170 \mathrm{~dB})$ radiated by launch vehicles at lift-off induce severe vibration on the launch vehicle structure and payload, and ground support equipment. Consequently the need to reduce acoustic levels from jet exhausts is paramount.

Water injection has been traditionally considered for the suppression of high noise levels from rocket exhausts in launch vehicle environments. For example, large amounts of water (of the order of $300,000 \mathrm{gpm}$ ) are used for the suppression of ignition overpressure (IOP) and lift-off noise during Space Shuttle launches. The water mass flow rate to the SRB exhaust mass flow rate ratio is maintained around one to two in order to meet payload design requirements of $145 \mathrm{~dB}$ (Dougherty \& Guest ${ }^{4}$, Jones ${ }^{5}$ ). Water injection could reduce noise by as much as 8-12 dB. Such a high level of reduction includes reductions in the turbulent mixing noise and shock-associated noise, the latter constituting the predominant component of noise reduction.

Water injection mitigates all the three components of jet noise: the turbulent mixing noise, the screech, and broadband shock noise. Two principal mechanisms leading to the diminution of jet noise by water injection are the 
reduction of jet velocity and jet temperature (Moriniere, Gervais \& Peube ${ }^{6}$ ). The decrease of jet velocity is occasioned through momentum transfer between the liquid and the gaseous phases, and the reduction of the jet temperature is achieved due to partial vaporization of the injected water (Zoppellaeri \& Juve ${ }^{7}$ ). The effect of water may also be regarded as effectively increasing the jet density (Jones ${ }^{5}$ ). Important velocity reductions are achieved within a few diameters of the nozzle exit. Noise reductions of the order of $10 \mathrm{~dB}$ are realized for both cold and hot jets (Zoppellaeri \& Juve, ${ }^{7,8}$.

Several design parameters influence the effectiveness of noise reduction by water injection. These include water to jet mass flow rate ratio, axial injection location, water injection angle, number of injectors, method of injection (jet type or spray type), droplet size, water pressure, and water temperature. Optimal injection parameters need to be determined for the design of efficient water deluge system. Data of Zoppellari \& Juve ${ }^{5}$ and of Norum ${ }^{9}$ suggest that best noise reductions of the order of 10 to $12 \mathrm{~dB}$ are obtained at injection angles of 45 to $60 \mathrm{deg}$., injection near the nozzle exit (especially for shock-containing jets), and high mass flow rates. Also the optimum number of injectors appears to be around eight. Experiments by Krothappalli et al. ${ }^{10}$ and Greska $\&$ Krothapalli ${ }^{11}$ and Arakeri et al. ${ }^{12}$ at reduced water mass flow rate ratios (about 0.1 ) through the use of microjets show sizable noise reduction for application to aircraft jet engines.

Experiments with water injection suggest that the mass flow rate ratio appears to be an important parameter. Tests conducted with water to jet mass flow rate ratios up to four (Zoppellari \& Juve ${ }^{7}$ ) reveal that significant noise reductions can be achieved at high water flow rate ratio. In the case of cold jets, beyond a critical mass flow rate ratio, the velocity reduction and thus the noise reduction is small. For hot jets, only a fraction of the liquid is effective in reducing the air jet velocity due to drop evaporation. At low water flow rates, it is possible to reduce the shock associated noise significantly. At higher mass flow rates, momentum transfer principally affects the mixing noise over a broad range of frequency.

At considerably high mass flow rates, the benefit of velocity reduction of the air jet by momentum transfer between the two phases is partly opposed by the emergence of new parasitic sources linked to water injection, which include the impact noise of air on the water jets, fragmentation of these water jets, and unsteady movement of the droplets. A compromise can be found between significant penetration of water jet into the air jet and low impact noise. A significant parameter is the velocity component of water jets that is perpendicular to the air jet. If this component is high, water penetrates deeply into the air jet and mixing takes place rapidly. If this component is small, water does not produce significant drag and impact noise.

In view of the importance of water injection in jet noise suppression, a theoretical understanding of the mechanism of noise reduction is useful in the design and optimization of water deluge systems for launch acoustics application. Based on control volume formulation a simple one-dimensional analytical model has been recently reported by the authors (Kandula and Lonergan ${ }^{13}$ ) for estimating jet mixing noise suppression due to water injection. The method is based on the conception of effective jet properties, and is found to yield satisfactory agreement with the test data for hot perfectly expanded supersonic jets with regard to turbulent mixing noise reduction with water injection over a wide range of water to jet mass flow rate ratios.

In the presence of water injection, broadband shock noise reductions are considerably higher than those due to turbulent mixing noise. Thus an accurate estimation of the broadband shock noise reduction is important in the design of the water deluge systems for jet noise mitigation at launch sites. In this paper, the method of effective jet properties will be applied (extended) to the prediction of broadband shock noise reduction with water injection in imperfectly expanded supersonic jets.

\section{Analysis}

\section{A. Broadband Shock Noise Reduction}

The intensity of broadband shock noise is primarily a function of the nozzle pressure ratio and largely independent of the temperature ratio (Krothapalli et al. ${ }^{10}$ ). Harper-Bourne and Fisher ${ }^{14}$ found that for a given 
radiation direction the measured OASPL due to shock-associated noise scales with the Prandtl-Glauert parameter $\beta$ as:

$$
p^{2} \sim \beta^{4}
$$

where

$$
\beta=\sqrt{M_{j}^{2}-1}
$$

and $M_{j}$ is the fully expanded jet Mach number. The parameter $\beta$ characterizes the pressure jump across a normal shock with an n upstream Mach number $M_{j}$.

In the presence of water injection, the effective jet properties (jet velocity, temperature, Mach number, etc.) near the exit are obtained from the theory proposed in Kandula and Lonergan ${ }^{13}$. In the present context, the effective jet Mach number is obtained as a function of the water to jet mass flow rate ratio. Thus the reduction in OASPL can be estimated as

$$
\triangle S P L \sim 20 \log \left(\frac{M_{j 1}^{2}-1}{M_{j 2}^{2}-1}\right)
$$

where the subscripts 1 and 2 respectively refer to the original and effective jet exit conditions.

Eq. (2) yields the noise reduction due to water injection as applied to a single isolated shock in the jet. The consideration of noise reduction in the multiple shock system (which is usually the case; typically with 5 or 6 shock cells) is very complex. Thus it is assumed in the present analysis that the overall noise reduction is proportional to the number of shock cells downstream of the water injection station, $n_{s d}$. That is,

$$
\triangle S P L_{\text {total }}=n_{s d} \Delta S P L
$$

where the quantity $\triangle S P L$ is provided by eq. (2a).

\section{B. Effective Jet Exit Conditions}

\section{Effective Jet Mach Number}

In the following, we briefly review the results for the effective jet properties derived in Kandula \& Lonergan (2007) on the basis of a control volume formulation (Fig. 3).

An expression for the effective jet Mach number is given by

$$
\frac{M_{j 2}}{M_{j 1}}=\left(\frac{u_{j 2}}{u_{j 1}}\right)\left(\frac{\rho_{j 2}}{\rho_{j 1}}\right)^{1 / 2}
$$

where the effective jet velocity and jet density are obtained as follows.

\section{Effective Jet Velocity}

From the momentum equation in conjunction with the continuity equation, an expression of the jet velocity ratio can be obtained as: 


$$
\frac{u_{j 2}}{u_{j 1}}=\frac{1}{\left(1+\eta \frac{\dot{m}_{w}}{\dot{m}_{j 1}}\right)}[1-\phi+\psi]
$$

In the above, the quantity $\eta$ represents the fraction of water flow rate that is evaporated. The quantity $\phi$, related to the particle drag force, can be expressed as

$$
\begin{gathered}
\phi=\frac{F_{d}}{\rho_{j 1} u_{j 1}^{2} A_{j 1}}=\psi\left(\dot{m}_{w} / \dot{m}_{j 1}\right)(1-\eta) \\
\psi=\frac{3}{2}\left(\frac{\rho_{j 1}}{\rho_{p}}\right)\left(\frac{d_{j 1}}{d_{p}}\right)^{3} n \frac{1}{2} C_{D}\left(\frac{\operatorname{Re}_{p}}{\operatorname{Re}_{j 1}}\right)^{2}
\end{gathered}
$$

Here the quantity $n$ denotes the length of the control volume in terms of the jet exit diameters $\left(n=L / d_{j 1}\right)$. The nonlinear drag law for $C_{D}$ is obtained from a correlation (White ${ }^{15}$ ).

The quantity $\sigma$, representing the effect of droplet evaporation, can be written as

$$
\frac{\eta \dot{m}_{w} u_{p}}{\rho_{j 1} u_{j 1}^{2} A_{j 1}}=\eta\left(\frac{\dot{m}_{w}}{\dot{m}_{j 1}}\right)\left[1-\frac{\operatorname{Re}_{p}}{\operatorname{Re}_{j 1}} \frac{d_{j 1}}{d_{p}}\right]
$$

where $\operatorname{Re}_{j 1}$ is the jet Reynolds number, and $\operatorname{Re}_{p}$ the droplet Reynolds number defined by

$$
\operatorname{Re}_{j 1}=\frac{\rho_{j 1} u_{j 1} d_{j 1}}{\mu_{j 1}}, \quad \operatorname{Re}_{p}=\frac{\rho_{j 1}\left(u_{j 1}-u_{p}\right) d_{p}}{\mu_{j 1}}
$$

and $d_{p}$ is the droplet diameter.

\section{Effective Jet Density}

The density ratio is evaluated from

$$
\rho_{j 2} / \rho_{j 1}=T_{j 1} / T_{j 2}
$$

where

$$
\begin{gathered}
\frac{T_{j 2}}{T_{j 1}}=\frac{1}{\left(1+\eta \frac{\dot{m}_{w}}{\dot{m}_{j 1}}\right)}\left[1+\frac{u_{j 1}^{2}}{2 c_{p j} T_{j 1}}-\frac{F_{D} u_{p}}{c_{p j} T_{j 1}}\right]-\frac{u_{j 2}^{2}}{2 c_{p j} T_{j 1}} \\
\frac{u_{j 1}^{2}}{2 c_{p j} T_{j 1}}=\frac{\gamma-1}{2} M_{j 1}^{2}
\end{gathered}
$$


An expression for the evaporation fraction $\eta$ as

$$
\frac{1}{\eta}=1+\frac{\operatorname{Pr}}{N u} \frac{\operatorname{Re}_{j 1}}{\left(\frac{d_{j 1}}{d_{p}}\right)^{2}} \frac{1}{\frac{3}{2}\left(\frac{\rho_{j 1}}{\rho_{p}}\right) n}\left[\frac{h_{f g}}{c_{p j}\left(T_{j e}-T_{s a t}\right)}\right]
$$

where Pr is the Prandtl number of the gas (taken as 0.7). Eq. (27) suggests that the evaporation factor $\eta$ is independent of the water to jet mass flow rate ratio. Ranz-Marshall correlation (Ranz and Marshall ${ }^{16}$ ) for heat transfer to a sphere in convective flow is considered for the Nusselt number $N u$ in eq. (11).

\section{Effective Jet Cross Sectional Area}

The effective jet exit cross sectional area becomes

$$
\frac{A_{j 2}}{A_{j 1}}=\left(\frac{\rho_{j 2}}{\rho_{j 1}}\right)\left(\frac{u_{j 1}}{u_{j 2}}\right)\left(1+\eta \frac{m_{w}}{m_{j 1}}\right)
$$

\section{Droplet Diameter and Droplet Reynolds Number}

In the foregoing equations, the droplet diameter $d_{p}$ and the droplet Reynolds number $\operatorname{Re}_{p}$ remain as unknowns. A direct calculation of these quantities is very complex, requiring extensive simulations. On the basis of the postulate of invariant groups, the droplet diameter and droplet Reynolds number are shown to be given by

$$
\begin{gathered}
\frac{d_{j 1}}{d_{p}}=\left[\frac{1}{c_{1}} \frac{\operatorname{Re}_{j 1}}{\left(\rho_{j 1} / \rho_{p}\right)}\right]^{1 / 2} \\
\left.\operatorname{Re}_{p}=c_{2} \frac{\operatorname{Re}_{j 1}}{\left(d_{j 1} / d_{p}\right.}\right)
\end{gathered}
$$

Thus the unknown quantities $\operatorname{Re}_{p}$ and $d_{j 1} / d_{p}$ are determined in terms of the adjustable constants $c_{1}$ and $c_{2}$. In view of the complexity with regard to the knowledge of droplet diameter and drop Reynolds number, it is postulated that the constants $c_{1}$ and $c_{2}$ are invariant (Kandula and Lonergan ${ }^{13}$ ). These constants may be established by a correlation with available test data.

The above analysis suggest that the effective jet conditions in the presence of water injection are dependent primarily on the water-to-gas mass flow rate ratio, and independent of momentum flux ratio, the latter being governed primarily the penetration depth of the injected water normal to the jet. A correlation of the analysis with the test data of Norum ${ }^{9}$ for hot supersonic turbulent mixing noise reduction at $M_{j}=1.45$ yields the values of the invariants $c_{1}$ and $c_{2}$ as (Kandula and Lonergan ${ }^{13}$ ) 


$$
c_{1}=5, \quad c_{2}=0.05
$$

These values for the constants $c_{1}$ and $c_{2}$ are considered here. The ratio of water jet mass flow rate to the jet mass flow rate $\left(\dot{m}_{w} / \dot{m}_{j 1}\right)$ is varied to a maximum value of about 0.825 .

\section{Typical Distributions of Effective Jet Properties}

Some typical results for the effective jet properties as presented in Kandula and Lonergan ${ }^{13}$ are shown here. Illustrated in Fig. 4a is the dependence of the effective jet Mach number as a function of the water mass flow rate at $\operatorname{Re}_{j 1}=10^{7}$. The trend is similar to that indicated for the effective jet temperature. The results suggest that below a water flow rate ratio of one, the effective jet temperature is almost independent of the jet exit Mach number. The jet Reynolds number effect on the effective jet Mach number is illustrated in Fig. 4b. The change in effective jet Mach number is relatively less sensitive to jet Reynolds number.

The results show that the effective jet density increases with the flow rate, and with an increase in the jet exit Mach number. Calculations suggest that the jet cross sectional area increases with the water flow rate. At a fixed flow rate ratio, the effective jet area decreases with an increase in the jet exit Mach number.

\section{Results and Discussion}

\section{A. Comparisons with Experimental Data}

For comparison purposes, we consider here the test data of Norum 9 for cold over-expanded jet broadband shock noise reduction with water injection (case D). The jet issues from a convergent-divergent (CD) nozzle. For the cold operation of the Mach 1.5 CD nozzle, the highest nozzle pressure ratio (NPR) that can be achieved prior to the onset of dominant screech is about 2.27 , corresponding to $M_{j}=1.15$ at which broadband shock noise is measured.

Acoustic data are obtained with injection angles of $45 \mathrm{deg}$ and $60 \mathrm{deg}$, with the injection at 60 deg yielding a somewhat higher noise reduction. The axial injection location is adjusted by varying the injector ring corresponding to known positions of the shocks in the over-expanded jet plume.

Fig. 5a shows the dependence of SPL reduction with the water mass flow rate with the injection station upstream of shock cell-1. A total of five shock cells are considered here. The theory shows a nearly linear dependence of SPL reduction with the mass flow rate, while the data suggests a saturation trend after an initially linear increase. In the linear range of the data (abscissa of 0 to 0.22 ), the theory suffers a maximum error of about $2.5 \mathrm{~dB}$.

A comparison for the injection upstream of shock cell-2 is presented in Fig. $5 b$. The trend is similar to that shown in Fig. 4a. However, the maximum error in the linear range (abscissa of 0 to 0.22 ) is about $1.5 \mathrm{~dB}$. Results of comparison for injection upstream of shock cell-3 are exhibited in Fig. 5c. Again the trend is similar to that discussed with regard to Fig. $4 \mathrm{a}$, but the theory agrees much closer to the data in the linear range (abscissa of 0 to 0.22 ), with a maximum error of $0.5 \mathrm{~dB}$.

\section{B. Deduction of Parasitic Noise}

Fig. 6 shows a composite plot for the case of water injection upstream of shock cell-1. In this plot, the original data are resolved (extrapolated) into two linear segments - curve-1 and curve-2. Curve-1 extrapolates the second linear segment of the data, and curve-2 extrapolates the third linear segment of the data. It is interesting to note that the slope of curve- 2 is very close to that predicted by the theory for the broadband shock noise. We are inclined to believe that the difference between curve- 1 and curve- 2 represents the parasitic noise, whose magnitude is reflected by a separate curve. With this conjecture, the parasitic noise seems to commence (manifest itself) at a mass flow rate 
ratio beyond 0.22 , and increases linearly with the mass flow rate thereafter. The parasitic noise increases to as high as $7 \mathrm{~dB}$ for a mass flow rate ratio of 0.5 .

\section{Conclusion}

An approximate formulation has been developed for the prediction of broadband shock noise reduction by water injection. The proposed formulation agrees satisfactorily with the test data for water injection into an over-expanded supersonic jet. The results suggest that beyond certain mass flow rate, parasitic noise due to water impact becomes manifest. This result points to the possibility of the existence of an optimum injected water mass flow rate for shock noise reduction purposes. 


\section{References}

'Crighton, D.G., Orderly structure as a source of jet exhaust noise: Survey lecture, in Structures and Mechanisms of Turbulence II (ed. H. Fiedler), Lecture Notes in Physics, Springer, Vol. 76, 1977, pp. 154-170.

${ }^{2}$ Seiner, J.M., Advances in high speed jet aeroacoustics, AIAA-84-2275, 1984.

${ }^{3}$ Pao, S.P., and Seiner, J.M., Shock-Associated noise in supersonic jets, AIAA Journal, Vol. 21, No. 5, pp. 687693,1983

${ }^{4}$ Dougherty, N.S., and Guest, S.H., A correlation of scale model and flight aeroacoustic data for the Space Shuttle vehicle, AIAA-84-2351, AIAA/NASA $9^{\text {th }}$ Aeroacoustics Conference, Williamsburg, Virginia, October 1984.

${ }^{5}$ Jones, J.H., Scaling of ignition startup pressure transients in rocket systems as applied to the space shuttle overpressure phenomenon, JANNAF $13^{\text {th }}$ Plume Technology Meeting, CPIA-PUB-357, Vol. 1, 1982.

${ }^{6}$ Moriniere, V., Gervais, Y., and Peube, J.-L, Numerical calculation of spectrum emission and jet noise reduction by injection of mass, Internoise 95, Newport Beach, pp. 273-276, July 1995.

${ }^{7}$ Zoppellari, E., and Juve, D., Reduction of jet noise by water injection, AIAA-97-1622, 1997.

${ }^{8}$ Zoppellari, E., and Juve, D., Reduction of hot jet noise by water injection, AIAA-98-2204, 1998.

${ }^{9}$ Norum, T.D., Reductions in multi-component jet noise by water injection, AIAA-2004-2976, $10^{\text {th }}$ AIAA/CEAS Aeroacoustics Conference, Manchester, Great Britain, May 2004.

${ }^{10}$ Krothapalli, A., Venkatakrishnan, L., Lourenco, L., Greska, B., and Elavarasan, R., Turbulence and noise suppression of a high-speed jet by water injection, J. Fluid Mechanics, Vol. 491, 2003, pp. 131-159.

${ }^{11}$ Geska, B., and Krothapalli, A., Jet noise reduction using aqueous microjet injection, AIAA-2004-2971, 10 $0^{\text {th }}$ AIAA/CEAS Aeroacoustics Conference, Manchester, Great Britain, May 2004.

${ }^{12}$ Arakeri, V.H., Krothapalli, A., Siddavaram, V., Arkisler, M., and Lourenco, L., On the use of microinjectors to suppress turbulence in a Mach 0.9 axisymmetric jet, J. Fluid Mech., Vol. 490, 2003, pp. 75-98.

${ }^{13}$ Kandula, M., and Lonergan, M., Effective jet properties for the prediction of turbulent mixing noise reduction by water injection, AIAA-2007-3645, 13 ${ }^{\text {th }}$ AIAA/CEAS Aeroacoustics Conference, Rome, may 2007.

${ }^{14}$ Harper-Bourne, M., and Fisher, M.J., The noise from shock waves in supersonic jets, Noise Mechanisms, AGARD CP-131, paper 11, March 1974.

${ }^{15}$ White, F.M., Viscous Fluid Flow, $2^{\text {nd }}$ ed., McGraw-Hill, New York, 1991, p. 182.

${ }^{16}$ Ranz, W.E., and Marshall, W.P., Chemical Eng. Prog. , Vol. 48, No. 141, 1952, p. 173. 


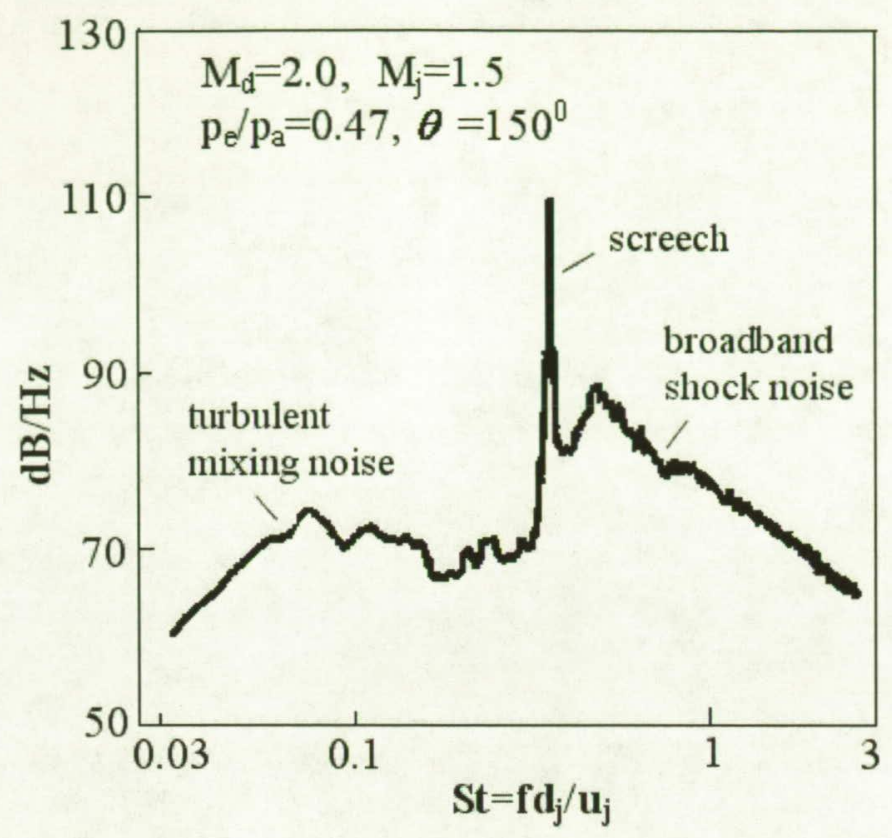

Fig. 1 A typical narrowband farfield shock noise spectrum (adapted from Seiner 1984).

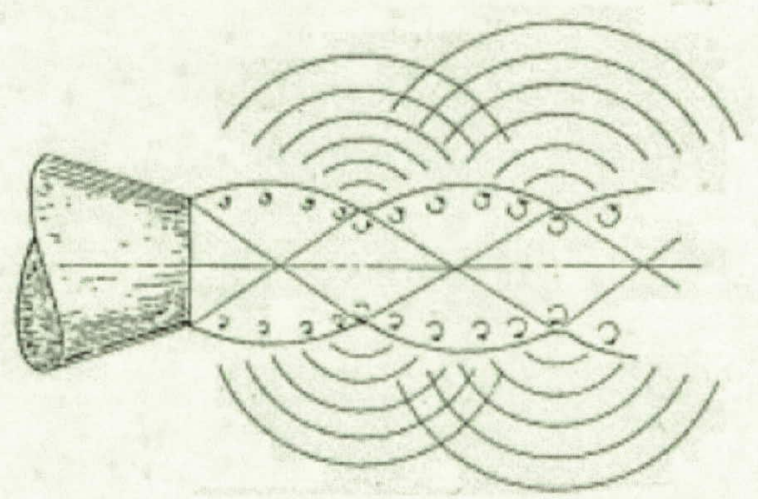

Fig. 2 Representation of shock-associated noise (adapted from Pao and Seiner 1983). 


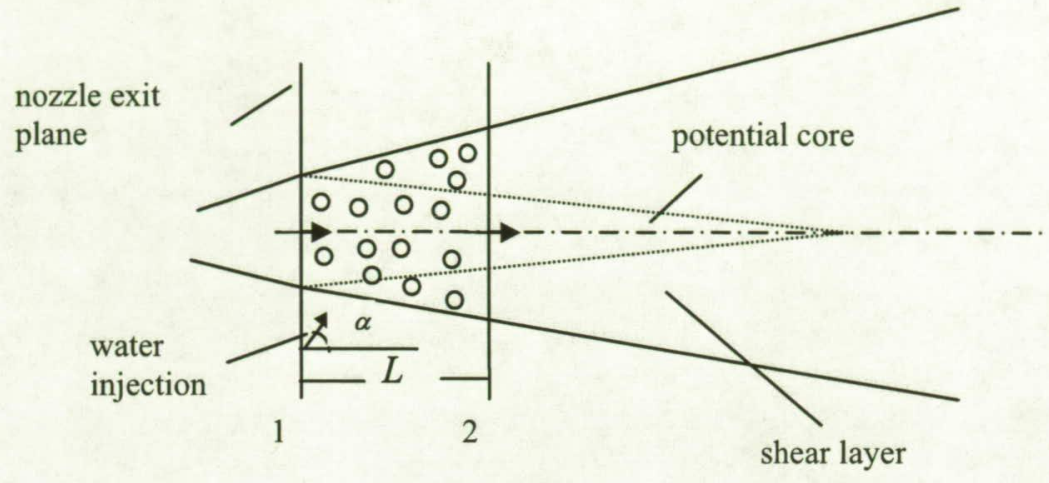

Fig. 3 Schematic of the jet configuration with water injection (shocks not shown).

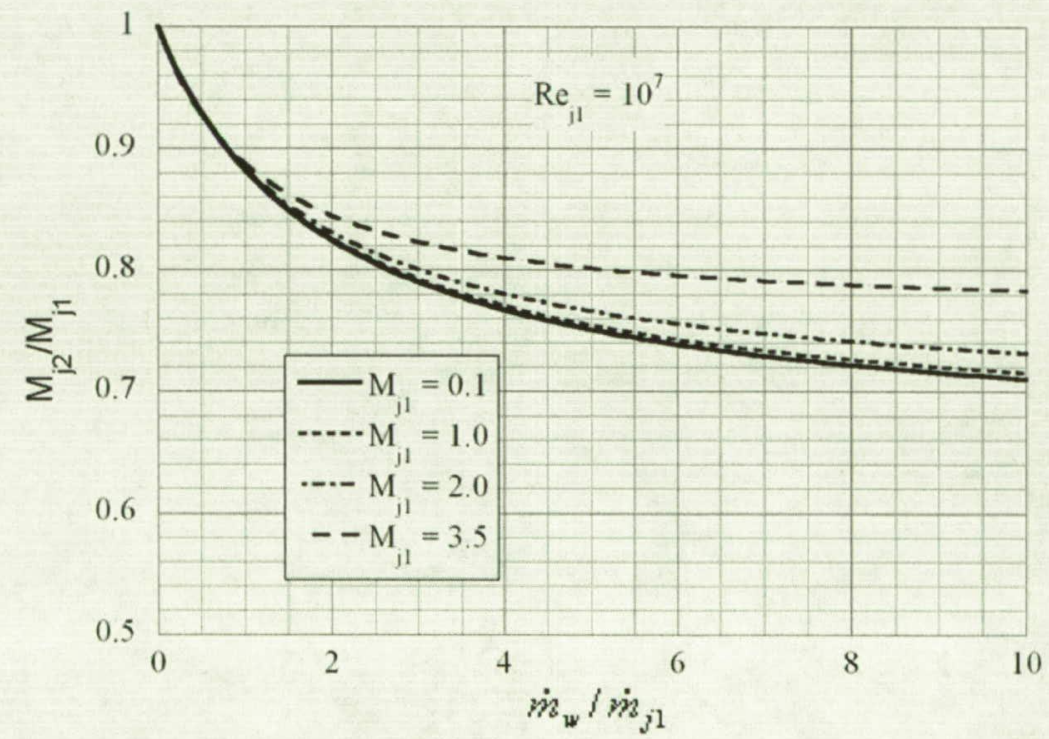

Fig. 4a Variation of effective jet Mach number with the water mass flow rate. 


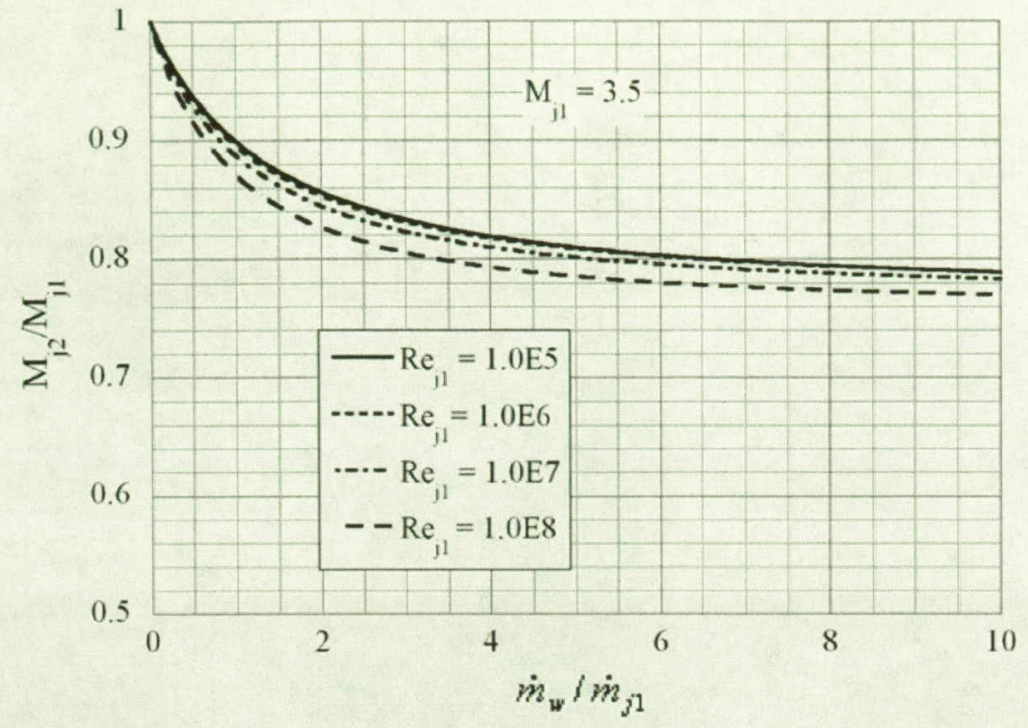

Fig. 4b Dependence of effective jet Mach number on jet Reynolds number.

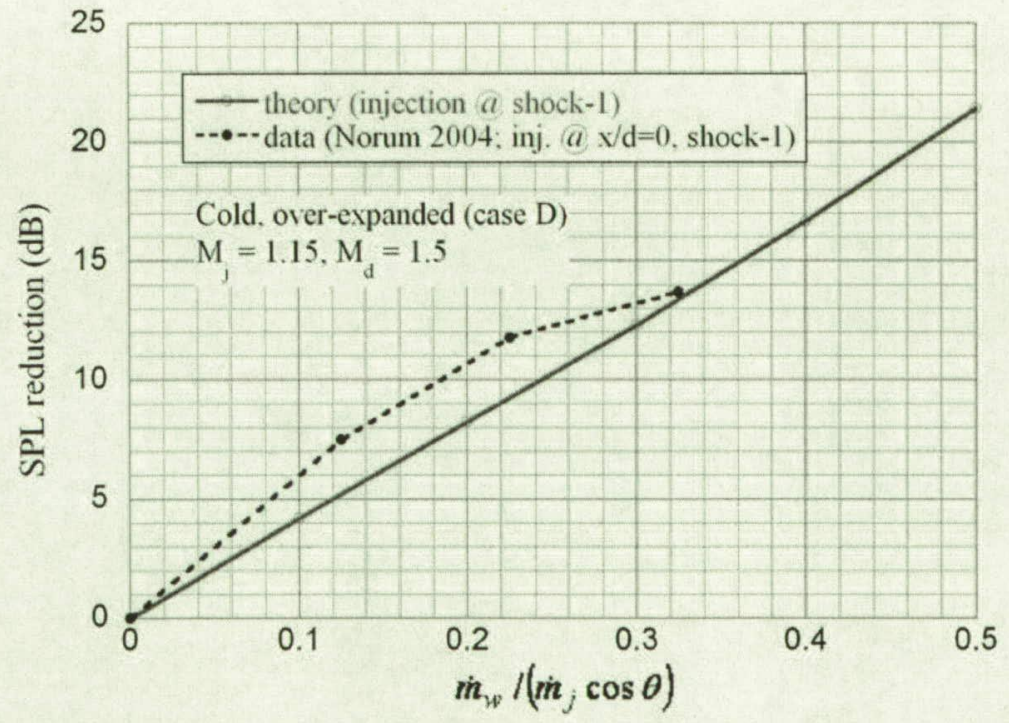

Fig. 5a Dependence of SPL reduction with the water mass flow rate with injection upstream of shock cell-1. 


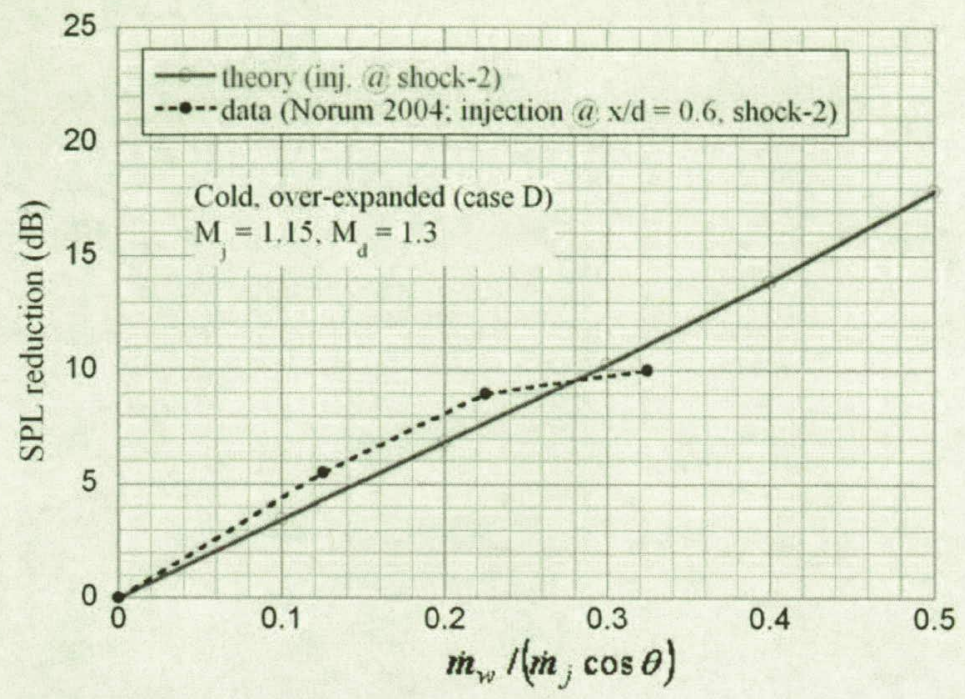

Fig. $5 \mathrm{~b}$ Dependence of SPL reduction with the water mass flow rate with injection upstream of shock cell-2.

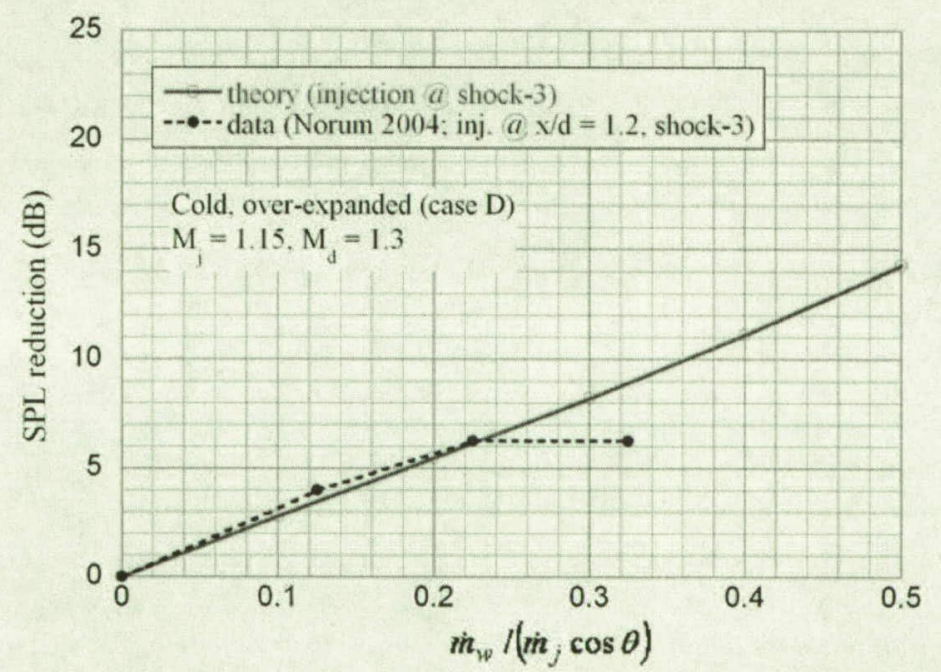

Fig. $5 \mathrm{c}$ Dependence of SPL reduction with the water mass flow rate with injection upstream of shock cell-3. 


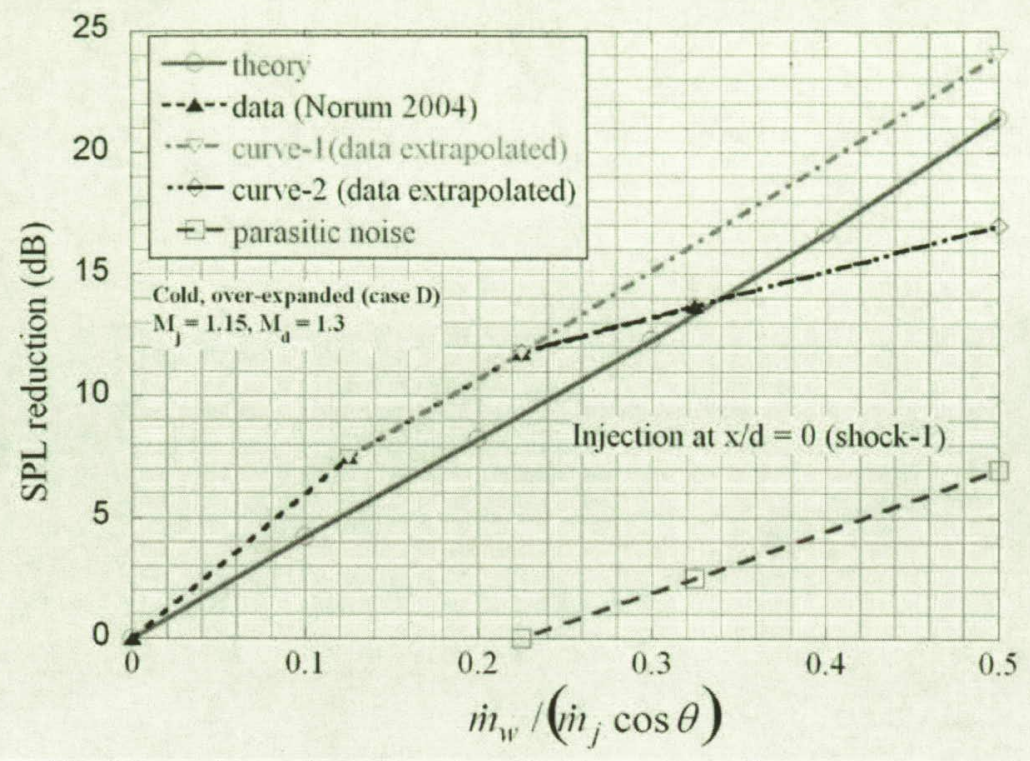

Fig. 6 Dependence of parasitic noise with the water mass flow rate. 


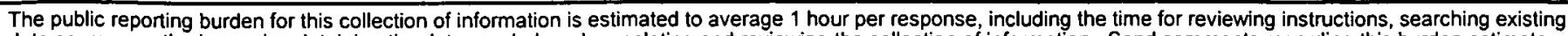

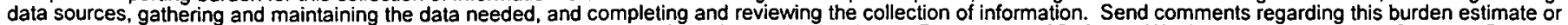

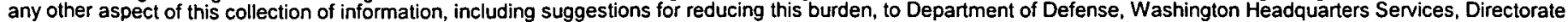
for Information Operations and Reports (0704-0188), 1215 Jefferson Davis Highway, Suite 1204, Arlington, VA 22202-4302. Respondents should be aware that

notwithstanding any other provision of law, no person shall be subject to any penalty for failing to comply with a collection of information if it does not display a currently

valid OMB control number.

PLEASE DO NOT RETURN YOUR FORM TO THE ABOVE ADDRESS

1. REPORT DATE (DD-MM-YYYY) 2 2. REPORT TYPE

conference paper

\section{TITLE AND SUBTITLE}

Estimation of Broadband Shock Noise Reduction in Turbulent Jets by Water Injection

3. DATES COVERED (From - To)

5a. CONTRACT NUMBER

NAS10-03006

5b. GRANT NUMBER

5c. PROGRAM ELEMENT NUMBER

5d. PROJECT NUMBER

6. AUTHOR(S)

M. Kandula

M.J. Lonergan

5e. TASK NUMBER

5F. WORK UNIT NUMBER

7. PERFORMING ORGANIZATION NAME(S) AND ADDRESS(ES)

ASRC Aerospace

8. PERFORMING ORGANIZATION REPORT NUMBER

ASRC-5211

Kennedy Space Center, FL 32899

9. SPONSORING/MONITORING AGENCY NAME(S) AND ADDRESS(ES)

National Aeronautics and Space Administration

NE-M1

Kenndey Space Center, FL 32899

10. SPONSORING/MONITOR'S ACRONYM(S)

NASA KSC

11. SPONSORING/MONITORING REPORT NUMBER

\section{DISTRIBUTION/AVAILABILITY STATEMENT}

\section{SUPPLEMENTARY NOTES}

\section{ABSTRACT}

The concept of effective jet properties introduced by the authors (AIAA-2007-3645) has been extended to the estimation of broadband shock noise reduction by water injection in supersonic jets. Comparison of the predictions with the test data for cold unerexpanded supersonic nozzles shows a satisfactory agreement. The results also reveal the range of water mass flow rates over shich saturation of mixing noise reduction and existence of parasitic noise are manifest.

\section{SUBJECT TERMS}

Broadband shock noise reduction, Water injection, parasitic noise, supersonic nozzles

\begin{tabular}{|c|c|c|}
\hline \multicolumn{3}{|c|}{ 16. SECURITY CLASSIFICATION OF: } \\
\hline $\begin{array}{c}\text { a. REPORT } \\
\text { b. ABSTRACT }\end{array}$ & c. THIS PAGE \\
4 & 4 & 4 \\
\hline
\end{tabular}

17. LIMITATION OF
ABSTRACT
44

18. NUMBER 19b. NAME OF RESPONSIBLE PERSON

OF

PAGES

14

Max Kandula

19b. TELEPHONE NUMBER (Include area code)
(321) $867-4456$ 